\title{
Development and Initial Validation of the Social Work Values Inventory
}

\section{Cathy King Pike}

This article reports the development and initial validation of the Social Work Values Inventory (SWVI). The SWVI was developed by using six tasks compiled by the author from the general literature on instrumentation. They include (a) developing a definition of values, (b) using the literature to select those values to be measured by the instrument, (c) using a theory of instrument construction, (d) relating the definition of values to the actual instrument, (e) developing unambiguous stimuli, and (f) determining scaling and scoring techniques. Preliminary reliability estimates ranged from acceptable to good acrossfour data collections. Examinations of content, factorial, and construct validity provided excellent support of the instrument as a valid measure of social work practice values.

Values in social work are viewed as important to the continued development of the profession. Academics writing on social work's professional development have asserted that careful' enunciation of a professional focus with regard to values will provide unity and clarity to the profession (Bartlett, 1970; Boehm, 1958; Coyle, 1940; Gustafson, 1982; Lee, 1929; Popple, 1985; Reamer, 1993; Reid \& Popple, 1992; Rein, 1970; Specht, 1990). Values and their meaning for the profession are central to the arguments that have been presented for various professional focuses (Coyle, 1940; Gilbert \& Specht, 1974).

Values are regarded as essential aspects of the professional socialization of social workers. The acquisition of professional values is considered so important to social work that the Council on Social Work Education (CSWE) requires that both baccalaureate and master's programs seeking accreditation demonstrate that they "infuse throughout the curriculum the values and ethics that guide professional social workers in their practice" (CSWE, 1991, paragraph 5.4.5).

A number of studies in social work have examined values differences across educational levels and values change during educational processes. The results from these studies were mixed. Several researchers (Brown, 1970; Dyer, 1977; Hayes \& Varley, 1965; Judah, 1979; Lusk \& Miller, 1985; Varley, 1963; Yamatani, Page, Koeske, Diaz, \& Maquire, 1986) fiybd bi significant differences or changes in students' value positions as a function of education in social work. Other researchers (McLeod 7 Meyer, 1967; Merdinger, 1982; O'Connor \& Dalgleish, 1986; Sharwell, 1974; Web, Linn, Hirsh, Stein, \& Furdon, 1976) found significant positive differences and changes in students' value positions during educational processes and across educational levels. Two researchers (Cryns, 1977; Varley, 1968) found significant change in negative directions across educational levles. Moran (1989) and Wodarski, Pippin, and Daniels (1988) found mixed results in their studies of professional socialization and students' values positions. 
In addition to their role in professional socialization, values are viewed as important components of decision making in practice. Levy (1972) discussed the importance of values with respect to their impact and consequences for clients. Kugelman (1992) found that values and ethical stances were important to the way in which practice decisions were implemented. Although values are prominent criteria for making decisions in practice, their enactment in practice is varied and may depend on a balance between ideals and practice realities (Pilsecker, 1978), the influence of specific situations (Felkenes, 1980; Kassel \& Kane, 1980; Sainsbury, 1982), and the personal values of social workers (Thomas, 1986).

A variety of instruments have been used to measure values in social work. Many of these instruments were developed and validated as attitude measures in other disciplines. The instrument s often measured only one value or attitude. Despite this, those studies that used instruments developed in other disciplines to measure attitudes often had greater success in identifying significant changes in desired directions than studies in which values instruments developed in social work were used. This suggests the possibility that the state of the art of social work values instrumentation may be less evolved than in other disciplines in which the development of instruments has played a central role in knowledge development.

Despite the profession's sustained interest in values, little is known about how values are enacted in practice. Much of the instrument development on general, as well as social work, values is characterized by unclear conceptual frameworks and the use of measurement techniques that were developed for attitudinal measures (Pike, 1994). Four instruments have been developed to measure social work values (Abbott, 1988; Howard \& Flaitz, 1982; McLeod \& Meyer, 1967; Varley, 1963). Of these, only two are in current use (Abbott, 1988; Howard \& Flaitz, 1982). The instruments differ in their degree of psychometric precision, and all evidence flaws in the conceptual frameworks and in measurement decisions (pike, 1994). Although the social work values instruments generally can detect differences in values adherence between social workers and people in other professions, none has been able to distinguish differences between social workers at different levels of professional education. This inability to discern possibly subtle differences in values adherence between social work students at different levels of education may be due to instrumentation flaws rather than to anticipatory socialization, which has been posed as an explanation for findings that indicated an apparent lack of differences across educational levels (Abbott, 1988).

The purpose of this research was to develop an instrument that measures adherence to social work practice values and differentiates subtle differences in values adherence between social work students at varying levels of education, and, ultimately, between social workers in different settings. This article reports the development and initial validation of the Social Work Values Inventory (SWVI). The reader should be aware that the instrument is still under development and further psychometric testing is anticipated. Thus the psychometric findings that are reported in this article should be viewed as the preliminary results of an ongoing research effort. 


\section{The Social Work Values Inventory}

Six tasks from the general instrumentation literature were compiled by the author (Pike. 1994) to guide decisions for the conceptual, that is, theoretical, framework and measurement considerations. These six tasks include:

- developing a definition of values

- using the literature to select those values to be measured by the instrument,

- using a theory of instrument construction,

- relating the definition of values to the actual instrument,

- developing unambiguous stimuli, and

- determining scaling and scoring techniques (Pike, 1994). The following sections report how these six tasks were used in the development of the SWVI and the preliminary psychometric findings.

\section{Developing a Definition of Values}

Social work practice values were defined for the purpose of this research by using four conceptual steps. These included selecting a level of abstraction that reflected the research goals. determining whether terminal or instrumental values would make up the focus of the instrument. identifying the evaluative component of those values, and using words that conveyed the appropriate evaluative component for the values measured. Because the goal of instrumentation was to measure values related to the conduct of practice rather than client end-states, instrumental values composed the focus of instrument development.

For this instrument, the central decisions of respondents deal with the determination of how clients should be treated in given circumstances. Thus, evaluative words that related to these values include such as should or ought. Social work values were defined as modes of conduct to which social workers believe they should adhere as they relate to, treat, and otherwise act on behalf of clients. The values measured by the instrument were assumed to vary in the extent to which they are considered important and consequently upheld in given practice situations.

\section{Using the Literature to Select Values}

A review of the social work literature was completed to define the content domain and to select those values to be measured by the SWVI. The review included conceptual articles on social work values, social work value texts, and general practice methods texts. The literature review failed to reveal a consensus within the profession about those values considered essential to effective social work practice.

A content analysis conducted by the author was used to identify the most commonly cited values in the literature. This was accomplished by examining the phraseology used in the literature on social work values and by counting the number of citations for given values in conceptual articles, practice methods texts, and texts on values. The practice values cited in the literature were not articulated consistently. An exception to this was the value of confidentiality. 
Apparently ,the concept of confidentiality is presumed to be sufficiently understood so that no other words are necessary to state this value. Where it was clear that different authors referred to the same value but used phraseology that differed only slightly, the citations were treated as specifying the same value. Where there was a possibility that authors had described different values, the citations were treated as having described separate values.

The number and types of values cited in the literature differed substantially. The number of values cited ranged from 0 to 10, with an average of 3.9. Four values were cited most often in the literature: confidentiality, self-determination, dignity and worth of clients, and social justice. These four values met definitional criteria for inclusion in the SWVI, in that they were viewed as instrumental values relating to the general practice of social work.

The dimensions of the initial instrument were composed of the four values. Preliminary testing revealed that the Dignity and Worth scale loaded across the other three scales. Because dignity and worth seems to underlie the three remaining values, it may represent a value orientation rather than a value. This scale was dropped from the SWVI in order to maintain a focus on values and is not reported in this article.

\section{Using a Theory of Instrument Construction}

Content domain sampling theory (Nunnally, 1978; Nunnally \& Bernstein, 1994) provided the theoretical foundation for the generation of the SWVI items. In the content domain sampling method, a number of items are generated to represent each dimension of a given instrument. The objective is to acquire a representative sampling of a given domain. The items in a scale can vary in severity, intensity, or between related components of a domain. Within this variation, content domain sampling requires that all items in a given scale share some common feature or attribute.

The prototype instrument contained 85 items, with each scale containing at least 20 items. After an initial elimination of35 items, decisions were made to eliminate items only after careful examination of their performance in two pilot tests. In subsequent testing, the number of items was reduced, depending on the perfonnance of each item across at least two data collections. In some instances, items that might have been eliminated based on the results from one pilot test were identified in subsequent testing as useful indicators. Items that demonstrated a lack of usefulness in at least two stages of the research were deleted from the scales.

\section{Relating the Definition of Values to the Instrument}

Two strategies were used to denote the evaluative nature of the values. First, the general instructions for the SWVI asked respondents to indicate the degree (circle the number) to which the social worker described in the item should be oriented toward one position or the other. Second, each item developed for the SWVI contained the word should immediately preceding the presentation of the response categories. 


\section{Developing Unambiguous Stimuli}

The review of the literature revealed that conceptual articles and research reports were highly consistent across disciplines in noting the importance of situational context in values decision making (Abramson, 1985; Converse \& Presser, 1986; Dukes, 1955; Felkenes, 1980; Kluckhohn, 1951; Kugelman, 1992; Levy, 1972; Phillips, 1980; Pilsecker, 1978; Rokeach, 1973; Sainsbury, 1982; Salomon, 1967; Thomas, 1986). Accordingly, each item of the SWVI incorporates a contextual component through the use of situational vignettes. These vignettes were written to closely approximate the distribution of the five most common practice areas reported by Teare and Sheafor (1995) and by Gibelman and Schervish (1993). These five areas were family and children's services, health care, mental health, school social work, and services for the elderly.

Each vignette includes a client (or coUaterals) and a social worker who must make a decision about the value in question. The vignettes were written in the third person to minimize individual interpretations relative to one's practice context. For each vignette, a situation is described in which one of the three values included in the instrument is challenged or called into question. Items in two of the content domains (confidentiality and self-determination) range in severity of consequences from minimal risk of violation of the value to maximal risk. An item having a minimal risk of violation of the value in question incorporates a situation in which the social worker would have few or no negative consequences as a result of upholding the value. Maximal risk of violating the value refers to situations in which there would be extremely negative consequences for upholding a value, as in the case of severe physical harm or death to the client or another person. For the social justice scale, the item content ranges from conservative to socialist views of social justice (George \& Wilding, 1976; Tropman, 1989).

In addition to the use of a vignette format, the extremes of the response categories were anchored with descriptive statements. Anchoring was assumed to provide greater clarity to the response task.

\section{Determining Scaling and Scoring Techniques}

Previous research findings on values instrumentation (Alwin \& Krosnick, 1985; Braithwaite \& Law, 1985) suggested that ratings may be more effective than rankings in measuring values. Further, ratings are typically employed when multiple indicators are used to measure one construct. The rating method of scaling was selected as the scaling technique for the SWVI.

The instrument was scored by using a five-point scale with a graduated continuum of extreme positions on the value in question. A score of 5 indicates the extreme position in upholding the value in question, whereas a 1 represents the extreme position of violating the value. The midpoint of the scale represents no commitment to either of the extreme positions at the ends of the scale. A complete copy of the Social Work Values Inventory and scoring instructions are available from the author. 


\section{Preliminary Psychometric Findings}

Four data collections have been conducted in preliminary pilot tests of the SWVI. Three were conducted by the author (Pike, 1994), and one was conducted by Rice (1994/1995) with the author serving as a consultant to the research. Included in the samples for the research by Pike (1994) were small pilot samples of baccalaureate and master'S students $(n=24)$, field instructors $(\mathrm{n}=31)$, and a larger sample of NASW members $(\mathrm{n}=192$, response rate $=49 \%)$. Pike's first two samples were convenience samples. The NASW sample was a random sample that was proportionately stratified by the five most common practice settings in the NASW membership population (Gibelman \& Schervish, 1993; Teare \& Sheafor, 1995).

Sixty-two percent $(n=15)$ of the student sample were baccalaureate students. Most of the students were single $(\mathrm{n}=21,88 \%)$. The number of BSW courses that students had completed ranged from 0 to 10 , with a mean of 3.56 (median $=3.0$ ).

The field instructor sample was composed of individuals holding both the BSW and MSW degrees. The respondents averaged almost 15 years of social work experience. Most respondents reported a primary employment function of direct social work practice. Respondents had practice experience across the five most common NASW membership practice areas.

About 93\% ( $n=181)$ of the NASW respondents reported holding the MSW degree, whereas 2\% $(\mathrm{n}=4)$ reported holding only a BSW degree. Most respondents were in direct practice, averaging more than 16 years' experience. The typical respondent was female, white, middle-aged, and Democratic in political orientation.

Rice's (1994/1995) research included a large sample of baccalaureate and master's social work and business students. Rice randomly sampled social work programs and used proportionate stratification by type of program (BSW only, MSW only, both BSW and MSW). The business student sample in Rice's research was a convenience sample. Information about the sample characteristics of Rice's research is available elsewhere (Rice, 1994/1995).

Estimates of internal consistency reliability (Cronbach's alpha) were computed for each of the four samples. Missing values were deleted listwise for all analyses. Estimates of item-scale internal consistency were completed by including all items for each of the scales for the SWVI and then removing the item that would yield the highest alpha if deleted. This process was continued until no item remained in the scale that would yield a higher alpha if deleted. The alpha coefficients ranged from .53 to .84 (Pike, 1994). Table 1 lists the scale descriptive statistics, standard errors of measurement, and the coefficient alphas for the data collected by Pike. Rice (1994/1995) reported the following coefficient alphas for her study: Confidentiality, .60 , Self-Determination, .65, and Social Justice, . 78 .

The validity of the SWVI was examined using three methods. A retranslation process (Smith \& Kendall, 1963) examined item ambiguity and provided a quantitative estimate of the extent to which the scales of the SWVI were conceptually distinct. Rice (1994/1995) examined the construct validity of the SWVI, and a factor analysis of the instrument was completed (Pike, 1994). 
For the retranslation task, respondents $(n=22$, response rate $=58 \%$ ) were selected on the basis of their expertise in teaching, research, and/or practice in social work. Snowball sampling was used to develop the sample. Most of the respondents held at least an MSW degree. The respondents had substantial social work experience, averaging more than 21 years. The primary employment functions of direct practice, management/supervision, and education/training were about equally represented. Respondents reported having social work experience in a broad range of areas.

Respondents for the retranslation task sorted randomly arranged items into envelopes labeled with the value dimensions of the SWVI. Each item was typed, separated, and centered on threeinch slips of paper, with only one item on each slip of paper. An envelope for each of the value dimensions was provided for the sorting task. A label attached to the front of each envelope contained the name of the value dimension, the literary definition of the value, and the primary issue involved in the value being measured. Respondents placed each item into the envelope that they believed corresponded to the value represented by the item.

The extent to which respondents agreed that the items represented the scales for which they were constructed provided a quantitative estimate of the extent to which the scales were conceptually distinct. The criterion set for acceptable agreement about a given item was $70 \%$ for this research. The more typical criterion level for retranslation tasks is 50\% (Smith \& Kendall, 1963; Wollack, Wijting, Goodale, \& Smith, 1970). Thirty-seven of 41 total items (90\%) included in the retranslation task were sorted with at least $70 \%$ agreement between the participants.

Rice (1994/1995) examined the discriminant construct validity (Campbell \& Fiske, 1959) of the SWVI. Rice hypothesized that the SWVI scales would have low to moderate correlations with the Defining Issues Test (Rest, 1979), an instrument that measures moral reasoning and for which the psychometric characteristics have been well established. Rice (1994/1995) found the following Pearson correlation coefficients between the scales of the SWVI and the Defining Issues Test: Confidentiality, .30; Self-Determination, .14; and Social Justice, .25.

To further examine the discriminant construct validity, Rice (1994/1995) tested two important hypotheses:

- that scores for the SWVI would differ significantly between groups of social work and business students and

- that graduate social work students would score significantly higher on scales of the SWVI than baccalaureate social work students. Rice analyzed the data using a discriminant analysis and found that the SWVI significantly predicted group membership of social work and business students, with probabilities, based on the Wilks's Lambda, ranging from .0000 to .0010 for the three SWVI scales.

Rice then used analyses of variance (ANOVA) to examine differences in values adherence of social work students by educational level. These tests were statistically significant and were reported as follows: Confidentiality, F(3, 167) = 7.20, $\mathrm{P}<.0001$; Self-Determination, F(3, 167) $=$ 4.96, $\mathrm{P}<.0025$; and Social Justice, $\mathrm{F}(3,167)=8.27, \mathrm{p}<.0001$. A Tukey's Honestly Significant Difference test revealed that senior-level baccalaureate and graduate social work students had significantly higher scores on the three scales of the SWVI than entry-level 
baccalaureate students $(\mathrm{p}<.0167)$. Master's students scored significantly higher than both entrylevel and senior-level baccalaureate students on Self-Determination and Social Justice ( $\mathrm{p}<$ .0167).

A principal factors analysis was computed on the scales of the SWVI for the NASW sample (Pike, 1994), with the squared multiple correlations used as the initial communality estimates. The promax procedure was used to rotate the factors. The promax procedure "starts with an orthogonal structure ... and then determines an ideal pattern having greater spread than (the) orthogonal structure" (Nunnally \& Bernstein, 1994, p. 507). The procrustean rotation, that is, the oblique rotation of the promax procedure, was used to interpret the results. Table 2 contains the rotated factor structure.

An examination of the primary loadings of the items for each factor indicates that, for the most part, the items loaded consistently with their conceptualized scales. The first factor is composed primarily of self-determination items. Most of the items for Factor 2 are confidentiality items, and all but one of the items in Factor 3 are social justice items. Estimates of internal consistency for the scales as identified by the factor analysis were found to be comparable to those completed for the scales as constructed (Pike, 1994).

\section{Discussion and Applications to Social Work}

The findings of the validity estimates for the SWVI provide preliminary support of the instrument as a valid measure of social work practice values. The retranslation task provided strong evidence of conceptually distinct scales and item clarity, even though a high criterion for respondent agreement was used in the study. If the more typical 50\% criterion had been used, only one item would have failed to meet the criterion level for acceptable respondent agreement.

The SWVI performed exceedingly well in the portion of Rice's (1994/1995) study that examined the construct validity of the SWVI. It is reasonable from a conceptual standpoint to assume that values and moral development would have low to moderate correlations, because values decision making is associated to some degree with level of moral reasoning. However, a high correlation between the SWVI values scales and moral development would have indicated that the values scales were not measuring a conceptually distinct construct from that of moral development. Rice's finding of low, positive correlations for all three scales supported the discriminant construct validity of the three SWVI scales.

The findings by Rice (1994/1995) on group membership provided further support of the discrirninant construct validity of the SWVI. The SWVI should be able to distinguish differences in values between social work and nonsocial work students. Rice demonstrated that the SWVI is able to make this distinction, at least with regard to social work and business students.

The second finding (Rice, 199411995), that the SWVI can identify value differences within social work by educational levels, is particularly noteworthy not only as it relates to the validity ofthe SWVI but to social work values instrumentation in general. Until the development of the SWVI, no values instrument developed in social work has been able to identify value differences 
between social work students at varying educational levels. The finding of significant differences in the extent to which values were upheld for graduate, entry-level, and senior-level baccalaureate social work students supports what educators have known intuitively for many years: that social work students refine their values during the educational process. The finding also supports the theoretical literature on the process of professional socialization in social work and is congruent with the contention that inadequate measurement tools have prevented the identification of professional socialization processes in social work (Pike, 1994).

The results of the factor analysis for the NASW sample (Pike, 1994) provided preliminary support of the content and factorial validity for the three SWVI scales. In addition, when estimates of internal consistency reliability were computed for the factor scales, the results were comparable to those computed for the scales as conceptualized.

The estimates of internal consistency for the SWVI scales were disappointing. They were found to be at levels acceptable for basic research (Cohen \& Cohen, 1983). The scale standard errors of measurement remained low and relatively stable across all pilot tests, indicating good measurement error characteristics. It should be noted that the sample in which the lowest coefficient alphas were obtained was a very homogeneous sample of mostly female, Democratic NASW members who held, for the most part, an MSW degree. It is possible that sample homogeneity served to attenuate the levels of the coefficient alphas, and this possibility has been examined in other work (Hudson \& Pike, 1995). Another potential explanation is that the differences on values adherence between social work students, and particularly between experienced practitioners, are so subtle that restricted ranges yield an attenuation of the coefficient alphas that is unavoidable.

Two research issues seem relevant to the improvement of estimates of internal consistency for the SWVI. These issues refer to the number of response categories for items and the potential that ambiguity in the response task has been imposed by the random assignment of items to the instrument. An examination of the extent to which the number of response categories has contributed to homogeneity of responses should be completed, and a study of the arrangement of the items of the instrument should also be completed to evaluate ambiguity related to the format of the instrument.

In addition to the need for further examinations of scale internal consistency reliability of the SWVI, an examination of test-retest reliability should be undertaken. Social workers' value positions probably remain relatively stable over time. If so, test-retest reliability coefficients should be consistently high for the three SWVI scales. A study to examine coefficients of stability would address this question about the SWVI scales.

How values are implemented in practice can have far-reaching effects for clients, the agencies that employ social workers, and the social workers who must make decisions about values in practice. Effective decisions often rest upon a social worker's knowledge offederal and state laws, a judgment about the risks of violating or upholding a value, and consideration of the presumed priority of one value over another. Given the lack of consensus about which values are central to professional practice, prioritizing values currently is an individual judgment. For social 
workers who must make decisions that affect the lives of their clients, this is an unfortunate situation that can jeopardize careers in the event of error.

Research is needed to examine how experienced social workers make decisions about values in practice and the extent to which values adherence differs by practice setting and/or practice area. For instance, social workers in settings where the services are primarily involuntary-for example, agencies charged with providing protective services to children and adults-may differ significantly from social workers who provide only voluntary services in the extent to which they uphold self-determination and confidentiality. Practice area may influence values adherence for social workers. For instance, social workers providing hospice services may differ significantly in values adherence from social workers providing more traditional mental health services. Further research on values in practice can provide carefully delineated information and guidance to social workers in specific settings and practice areas on making effective decisions in their practices. Extensive research on values in practice ultimately can contribute to the development of more highly refined and relevant NASW ethical guidelines for social workers employed in a variety of settings and practice areas.

The psychometric findings for the SWVI that are described in this article should be viewed as preliminary indicators of the usefulness of the SWVI. Further psychometric research is necessary before making final judgments about the usefulness of the instrument. Values were once described as "the uncertain component in social work" (Judah, 1979, p. 79). It is hoped that by using sound instrumentation techniques, the profession, through carefully delineated practice research, will develop more certainty about the central aspect of values in social work.

[This space left blank intentionally] 
Tables

Table 1

Scale descriptive statistics, standard errors of measurement, and coefficient alphas for the SWVI pilot tests

Pilot Tests

\begin{tabular}{ccc}
\hline Student & Field instructor & NASW \\
$(n=24)$ & $(n=31)$ & $(n=192)$
\end{tabular}

Confidentiality

Items

8

Mean

26.22

Standard Deviation

7.01

Standard Errors of Measurement

2.78

Alpha

.84

Self-determination

Items

Mean

14

42.30

Standard Deviation

8.39

Standard Errors of Measurement

3.73

Alpha

.80

6

8

Social Justice

Items

11

47.26

Mean

Standard Deviation

6.32

Standard Errors of Measurement

2.65

Alpha

.82

5.23

5.25

2.47

.77

30.36

4.86

3.29

.54

9

\begin{tabular}{rr}
6 & \multicolumn{1}{c}{9} \\
17.87 & 30.47 \\
4.47 & 4.41 \\
3.10 & 3.01 \\
.70 & .54
\end{tabular}

6

25.00

10

42.77

3.71

4.23

1.49

2.91

.69

.53 
Table 2

Rotated Factor Structure (Correlations)

\begin{tabular}{|c|c|c|c|}
\hline ltem & Factor 1 & Factor 2 & Factor 3 \\
\hline Self-Determination6 & .5764 & .1582 & -.0298 \\
\hline Self-Determination22 & .4406 & -.1313 & -.1134 \\
\hline Self-Determination5 & .4542 & .0838 & .2465 \\
\hline Confidentiality 19 & .4113 & .2392 & .0976 \\
\hline Confidentiality 13 & .3245 & .0873 & .1849 \\
\hline Self-Determination 10 & .3142 & .2020 & -.0380 \\
\hline Selt-Determination25 & .2586 & .0955 & .1274 \\
\hline Confidentiality 15 & .0627 & .4953 & .0179 \\
\hline Confidentiality 14 & .0365 & .4834 & .0333 \\
\hline Confidentiality 11 & .0271 & .3494 & .1198 \\
\hline Confidentiality28 & .3155 & .. .3873 & .1253 \\
\hline Self-Determination 21 & .0946 & .3789 & .3013 \\
\hline Self-Determination3 & .1308 & .3119 & .0487 \\
\hline Confidentiality 17 & .2398 & .3501 & .1803 \\
\hline Self-Determination39 & .2683 & .3257 & .2065 \\
\hline Social Justice4 & .1173 & .2881 & .2611 \\
\hline Confidentiality 34 & .2257 & .2893 & .2221 \\
\hline Social Justice 33 & .1388 & .1343 & .4914 \\
\hline Social Justice35 & -.0644 & -.0354 & .4002 \\
\hline Social Justice 40 & .2964 & .1037 & .4338 \\
\hline Social Justice7 & .0380 & .0278 & .3377 \\
\hline Social Justice23 & .1378 & .1481 & .3558 \\
\hline Self-Determination 41 & .3985 & .2732 & .4142 \\
\hline Social Justice 1 & -.1728 & .0901 & .2721 \\
\hline Social Justice38 & .0465 & .1882 & .3078 \\
\hline
\end{tabular}




\section{References}

1. Abbott, A. A. (1988). Professional choices: Values at work. Silver Spring, MD: National Association of Social Workers.

2. Abramson, M. (1985). The autonomy-paternalism dilemma in social work practice. Families in Society, 66, 387-393.

3. Alwin, D. E, \& Krosnick, J. A. (1985). The measurement of values in surveys: A comparison of ratings and rankings. Public Opinion Quarterly, 49, 535-552.

4. Bartlett, H. M. (1970). The common base of social work practice. New York: National Association of Social Workers.

5. $\quad$ Boehm, W. W. (1958). The nature of social work. Social Work, 3(2), 10-18.

6. Braithwaite, V. A., \& Law, H. G. (1985). Structure of human values: Testing the adequacy of the Rokeach Value Survey. Journal of Personality and Social Psychology, 49, 250263.

7. $\quad$ Brown, M. J. (1970). Social work values in a developing country. Social Work, 15,107113.

8. Campbell, D. T., \& Fiske, D. W. (1959). Convergent and discriminant validation by the multitrait-multimethod matrix. Psychological Bulletin, 56, 81-105.

9. Cohen, J., \& Cohen, P. (1983). Applied multiple regression/correlation analyses for the behavioral sciences (2nd ed.). Hillsdale, NJ: Lawrence Erlbaum.

10. Converse, F. M., \& Presser, S. (1986). Survey questions: Handcrafting the standardized questionnaire. Newbury Park, CA: Sage.

11. Council on Social Work Education. (1991). Curriculum policy statement. Handbook of Accreditation Standards and Procedures. Alexandria, VA: Commission on Accreditation, Council on Social Work Education.

12. Coyle, G. L. (1940). Social work at the turn of the decade. In Proceedings of the National Conference of Social Work (pp. 3-26). Chicago: University of Chicago Press.

13. Cryns, A. G. (1977). Social work education and student ideology: A multivariate study of professional socialization. Journal of Education for Social Work, 13, 44-57.

14. Dukes, W. E (1955). Psychological study of values. Psychological Bulletin, 52, 24-50.

15. Dyer, P. M. (1977). How professional is the BSW worker? Social Work, 22, 487-492.

16. Felkenes, S. W. (1980). The social work professional and his ethics: A philosophical analysis. Dissertation Abstracts International, 41, 3725A.

17. George, v., \& Wilding, P. (1976). Ideology and social welfare. Boston: Routledge and Kegan Paul.

18. Gibelman, M., \& Schervish, P. H. (1993). Who we are: The social work labor force as reflected in the NASW membership. Washington, DC: National Association of Social Workers.

19. Gibert, N., \& Specht, H. (1974). The incomplete profession. Social Work, 19, 665-674.

20. Gustafson, J. M. (1982). Professions as "callings." Social Service Review, 56, 501-515.

21. Hayes, D., \& Varley, B. K. (1965). Impact of social work education on students' values. Social Work, 10(3), 40-46.

22. Howard, T. U., \& Flaitz, J. (1982). A scale to measure the humanistic attitudes of social work students. Social Work Research \& Abstracts, 18(4), 11-18. 
23. Hudson, W. w., \& Pike, C. K. (1995, March). Reliability and measurement error in the presence of homogeneity. Paper presented at the Council on Social Work Education, Annual Program Meeting, San Diego.

24. Judah, E. H. (1979). Values: The uncertain component in social work. Journal of Education for Social Work, 15, 79-86.

25. Kassel, S., \& Kane, R. (1980). Self-determination dissected. Clinical Social Work Journal, 8, 161-178.

26. Kluckhohn, C. (1951). Values and value-orientations in the theory of action: An exploration in definition and classification. In T. Parsons \& E. Shils (Eds.), Toward a general theory of action (pp. 388-433). Cambridge, MA: Harvard University Press.

27. Kugelman, W. (1992). Social work ethics in the practice arena: A qualitative study. Social Work in Health Care, 17(4),59-80.

28. Lee, P. R. (1929). Social work: Cause and function. In Proceedings of the National Conference of Social Work (pp. 3-20). Chicago: University of Chicago Press.

29. Levy, C. S. (1972). Values and planned change. Social Casework, 54, 488-493.

30. Lusk, M., \& Miller, D; (1985). A study of traditional and nontraditional graduate students of social work for values and cognitive development. Journal of Continuing Social Work Education, 3(2), 22-28.

31. McLeod, D. L., \& Meyer, H. J. (1967). A study of the values of social workers. In E. J. Thomas (Ed.), Behavioral science for social workers, (pp. 401-416). New York: Free Press.

32. Merdinger, J. M. (1982). Socialization into a profession: The case of undergraduate social work students. Journal of Education for Social Work, 18(2), 12-19.

33. Moran, J. R. (1989). Social work education and students' humanistic attitudes. Journal of Social Work Education, 25,13-19.

34. Nunnally, J. C. (1978). Psychometric theory (2nd ed.). New York: McGraw-Hill.

35. Nunnally, J. C., \& Bernstein, I. (1994). Psychometric theory (3rd ed.). New York: McGraw-Hill.

36. O'Connor, I., \& Dalgleish, L. (1986). The impact of social work education: A personal construct re-conceptualization. Journal of Social Work Education, 22(3), 6-30.

37. Phillips, D. G. (1980). Adherence to social work values and their enactment in practice among graduate students in psychology, social work, and psychiatric nursing. Dissertation Abstracts International,42,1797A.

38. Pike, C. K. (1994). Development of the social work values inventory (Doctoral dissertation, University of Alabama, 1994). Dissertation Abstracts International, 55(01), 1696A.

39. $\quad$ Pilsecker, C. (1978). Values: AprobJem for everyone. Social Work, 23, 54-57.

40. Popple, P. R. (1985). The social work profession: Areconceptualization. Social Service Review, 59, 560-567.

41. Reamer, F. G. (1993). The philosophical foundations of social work. New York: Columbia University Press.

42. $\quad$ Reid, P. N., \& Popple, P. R. (Eds.). (1992). The moral purposes of social work. Chicago: Nelson-Hall.

43. Rein, M. (1970). Social work in search of a radical profession. Social Work, 15(2), 1328.

44. Rest, J. R. (1979). Development in judging moral issues. Minneapolis: University of Minnesota Press. 
45. Rice, D. S. (1995). Professional values and moral development: The social work student (Doctoral dissertation, University of South Carolina, 1994). Dissertation Abstracts International, 56(01), 358A.

46. Rokeach, M. (1973). The nature of human values. New York: Free Press.

47. Sainsbury, E. (1982). Knowledge, skills and values in social work education. In R. Bailey \& P. Lee (Eds.), Theory and practice in social work (pp. 46-60). Oxford, England: Basil Blackwell.

48. Salomon, E. L. (1967). Humanistic values and social casework. Social Casework, 48, 26-

32.

49. Sharwell, G. R. (1974). Can value be taught? A study of two variables related to orientation of social work graduate students toward public dependency. Journal of Education for Social Work, 10,99-105.

50. Smith, P. K., \& Kendall, L. M. (1963). Retranslation of expectations: An approach to the construction of unambiguous anchors for rating scales. Journal of Applied Psychology. 47, 149155.

51. Specht, H. (1990). Social work and the popular psychotherapies. Social Service Review, 64, 345-357.

52. Teare, R. J., \& Sheafor, B. S. (1995). Practice-sensitive social work education: An empirical analysis of social work practice and practitioners. Alexandria, VA: Council on Social Work Education.

53. Thomas, C. B., Jr. (1986). Values as predictors of social activist behavior. Human Relations, 39, 179-193.

54. Tropman, J. E. (1989). American values and social welfare: Cultural contradictions in the welfare state. Englewood Cliffs, NJ: Prentice-Hall.

55. Varley, B. K. (1963). Socialization in social work education. Social Work, 8(3), 102-109.

56. Varley, B. K. (1968). Social work values: Changes in value commitments of students from admission to MSW graduation. Journal of Education for Social Work, 4(2), 67-76.

57. Webb, N., Linn, M., Hirsh, K., Stein, S., \& Furdon, J. (1976). Changes in the values of social work students: Authoritarianism, dogmatism and alienation. Journal of Social Welfare, 3(3), 59-65.

58. Wodarski, J., Pippin, J., \& Daniels, M. (1988). The effects of graduate education on personality, values and interpersonal skills. Journal of Social Work Education, 24, 266-277.

59. Wollack, S., Wijting, J. P., Goodale, J. G., \& Smith, P. C. (1970). Weighting agreement responses by item scale values. Journal of Applied PsycJwlogy, 54, 174-175.

60. Yamatani, H., Page, M., Koeske, G., Diaz, C., \& Maguire, L. (1986). A comparison of extended and traditional master's of social work students: A repeated measures analysis. Journal of Social Work Education, 22(3), 43-51. 